\title{
Cloning of TaPRP from Wheat and Its Cold Tolerance Analysis in Transgenic Tobacco
}

\author{
Zhang Baolei ${ }^{1}$ Li Da $^{1}$, Zhang Weidong ${ }^{1,2}$, Liu Dasheng ${ }^{3}$, Gao Qingrong ${ }^{1,2} \&$ Tian Jichun ${ }^{1,2}$ \\ ${ }^{1}$ State Key Laboratory of Crop Sciences, Shandong Agricultural University, Taian City, Shandong Province, \\ China \\ ${ }^{2}$ Genetic and Breeding Department, Agronomy College, Shandong Agricultural University, Taian City, \\ Shandong Province, China \\ ${ }^{3}$ Institute of Environmental Sciences in Shandong Province, Jinan City, Shandong Province, China \\ Correspondence: Zhang Weidong, Genetic and Breeding Department, Agronomy College, Shandong \\ Agricultural University, Daizong street 61, Taian City, 271018, Shandong Province, China. E-mail: \\ zhangwd@sdau.edu.cn
}

Received: January 13, 2015 Accepted: March 9, 2016 Online Published: April 15, 2016

doi:10.5539/jas.v8n5p61 URL: http://dx.doi.org/10.5539/jas.v8n5p61

\begin{abstract}
TaPRP, a proline rich protein (PRP) cDNA, was cloned by RT-PCR from winter wheat. Nucleotide sequence analysis showed TaPRP is composed of $1137 \mathrm{bp}$ (378 amino acid residues with a Mr of $42.19 \mathrm{kD}$ ). TaPRP shows 92.6\%, 89.3\%, 73.0\%, and 73.3\% sequence homologies with $P R P$ genes from wheat, sorghum, rice, and maize, respectively. The deduced protein includes 170 prolines, presenting a normal $P R P$ primary structure. Expression vector pBI-TaPRP was constructed, in which TaPRP was driven by CaMV35S promoter and stopped by NospolyA. Tobaccos were transformed by Agrobacterium containing the constructed vectors. Three transgenic lines were confirmed by PCR detection and Southern blot. Under the same low temperature stress conditions, transgenic plants had lower conductivity rate compared with the non-transgenic plants, suggesting that cold tolerance in transgenic tobacco plants was improved. However, the different transgenic plants showed significant differences in cold resistant, and there also existed significant interactions between plant and treatment temperature. TaPRP might have an important role in wheat in cold adaptation process.
\end{abstract}

Keywords: $T a P R P$, gene clone, genetic transformation, transgenic tobacco, cold tolerance

\section{Introduction}

Proline-rich proteins (PRPs) exist widely in plant kingdom and represent one of the classes of the so-called cell wall structural proteins (Showalter, 1993). PRPs were distinctive tissue-specific and possess many differentl biological functions in plant, mainly involving in the formation of cell wall. A wealth of information exists regarding the expression patterns of some of the PRP genes. Four proline-rich protein genes were cloned from Nicotiana alata and expressed in pollen tube or style (Chen et al., 1993). MsPRP4, a proline-rich early nodulin from Mediccrgo trunccrtulcr, highly expressed in nodule meristematic cells and might involve in the evolutionary relationships between fabaceous plants and azotobacter (Wilson et al., 1993). Many chemicals in plant affected the PRPs expression level, such as, plant hormones (auxin, cytokinins, gibberellin, ethylene, abscisic acid), jasmonic acid and salicylic acid (Datta et al., 1993; Subramaniam et al., 1994; Ogawa et al., 1999). And many environmental factors, including salt stress (Deutch et al., 1995), water stress (Yu et al., 1996), wounding (Yasuda et al., 1997), and bacterial and fungal infections (He et al., 2002), could also improve the expression level of PRP. In addition, although these proteins may also participate in several developmental processes, such as pollination, wound healing, tissue culture, and secondary metabolites, little information on their expression patterns in these regards (Wilson et al., 1993; Wyatt et al., 1994).

At present, many researches had been documented on the structures, properties and biological functions of the PRPs, and the expression characteristics of these PRPs genes had also been reported in different plant tissues or under environmental stresses. However, limited information is available on these proteins in response to cold stress in wheat. In an effort to understand the role of the protein responding to cold stress, a proline rich protein (PRP) cDNA, TaPRP, was cloned and transformed into tobacco by Agrobacterium. Electrolyte leakages under 
cold treatments were analyzed in non-transgenic and transgenic plants to access these plants' cold tolerance. This research might be helpful to understand the functions of PRP proteins in plants, and lay foundation for the utilization of the proteins in wheat breeding.

\section{Materials and Methods}

\subsection{Plant Materials and Bacterium Strain}

The winter wheat cultivar "Shannong 12" was bred in Agronomy College, Shandong Agricultural University and was used as the experimental material. Seeds were surface-sterilized with $1 \%$ sodium hypochlorite for 5 min, washed with tap water, and soaked in distilled water for germination in incubator at $25{ }^{\circ} \mathrm{C}$. After germination, Seedlings were grown in pot filled with sand and cultured with Hoagland nutrient solution under controlled conditions $\left(28{ }^{\circ} \mathrm{C}\right.$ day $/ 23{ }^{\circ} \mathrm{C}$ night, $16 \mathrm{~h}$ photoperiod, $500 \mathrm{lmol} \mathrm{m}^{-2} \mathrm{~s}^{-1}$ photons, and $80 \%$ relative humidity). After 7 days of growth, the leaves of wheat were frozen in liquid nitrogen and preserved at $-80{ }^{\circ} \mathrm{C}$ until use. Nicotiana tabacun variety NC89, Escherichia coli strains DH5a, and Agrobacterium tumefaciens strain LBA4404 were preserved in laboratory.

\subsection{Tool Enzymes, Plasmids and Reagents}

Trizol regent for total RNA extraction was bought from Invitrongen; Restriction enzymes including BamHI, Sac I, and EcoR I, Taq DNA polymerase, DNaseI, T4 DNA ligase and cloning vector pGEMT-Easy were all bought from Shanghai Promega Company (Shanghai, China). The expressing vector pBI121 were preserved in laboratory. DNA marker, the plasmid separating kit and DNA reclaiming kit, DIG DNA Labeling and Detection Kit were provided by Boshang Biotech (Beijing, China). All other chemicals and molecular reagents were of analysis grade from TaKaRa (Dalian, China).

\subsection{RNA Isolation and Cloning of TaPRP cDNA}

Total RNA was extracted from wheat leaves with Trizol reagent (Invitrogen, USA) according to the manufacturer's instructions, treated with RNase-free DNaseI, then the DNaseI was removed according to the instructions of the supplier. The RNA was quantified on a spectrophotometer and visualized on $1.2 \%$ agarose/formaldehyde gel to ensure high quality.

The first strand of cDNA was synthesized from $5 \mu \mathrm{g}$ of total RNA by reverse transcription using Superscript RT II (Invitrogen) according to instructions. Several PRP genes in Poacere plants were obtained from literature and EST database, and DNA sequences were compared. Degenerate primers flanking the ORF frame were designed with Oligo 6.0 software and two restriction enzyme cutting sites, BamHI and SacI, were added into the primers respectively. The upper stream primer was: P1, 5'-GCG GAT CCA GCA ATG GC(T) GAG (A)GC A(G)C $\mathrm{A}(\mathrm{C}) \mathrm{G} \mathrm{C}(\mathrm{G}) \mathrm{C}$ T-3' and the down stream primer, P2: 5'-GAC GAG CTC GAG GCT (G)CC (A)GG ACG GGG (C)T-3'. A $25 \mu \mathrm{l}$ reaction mixture for PCR amplification was prepared containing the following reagents: $10 \times$ PCR Buffer $2.5 \mu \mathrm{L}, 5 \mathrm{mmol} \mathrm{L}{ }^{-1}$ dNTP $2 \mu \mathrm{l}$, the two above primers $10 \mathrm{mmol} / \mathrm{L} 1 \mu \mathrm{L}, 1.0$ unit of Taq polymerase; $5 \mu \mathrm{L}$ of cDNA sample and $16.5 \mu \mathrm{L}$ of PCR-Grade Water. PCR conditions were 5 min at $94{ }^{\circ} \mathrm{C}$ followed by 30 cycles of $94{ }^{\circ} \mathrm{C}$ for $45 \mathrm{~s}, 56{ }^{\circ} \mathrm{C}$ for $1 \mathrm{~min}, 72{ }^{\circ} \mathrm{C}$ for $1 \mathrm{~min}$ and final elongation at $72{ }^{\circ} \mathrm{C}$ for 10 $\min$.

PCR products were visualized by electrophoresis in $1 \%(\mathrm{w} / \mathrm{v})$ agarose gels. The aimed amplification fragments were recovered and purified with DNA reclaiming kit. The recovered DNA fragments were cloned into pGEMT-Easy vector and transferred into E. coli DH5a. After restriction enzyme treatments, DNA sequencing was performed in Shanghai Bioengineering Company. The sequences were analyzed with DNAMAN 5.2.9 Demo version. The obtained cDNA was designated as TaPRP.

\subsection{Construction of Plant Expression Vector and Gene Transformation}

PCR products were digested with BamHI and SacI, and inserted into pBI121 vector with the same digestion. TaPRP expression box was constructed with CaMV35S promoter, TaPRP sequence and NOS polyA terminator (Figure 1). The expression vector was transformed into E. coli DH5 $\alpha$. The correct clone pBI121-PRP was examined by PCR amplification and sequenced by Shanghai Bioengineering Company. Plasmid extraction, digestion, electrophoresis, ligation and E. coli transformation were manipulated according to Sambrook et al. (1989).

The resulted plasmids pBI121-PRP were transferred into Agrobacterium tumefaciens LBA4404 by the liquid nitrogen freeze thaw method (Wang et al., 1998). The tobacco plants were transformed by A. tumefaciens mediated gene transfer with leaf discs transformation method and the transformed plants were selected by kanamycin. Six tobacco plants were obtained after selection in $100 \mathrm{mg} / \mathrm{L}$ kanamycin. The six transformed 
tobacco plants and untransformed ones were all cultured on 1/2 MS medium. Shoots were generated from transformed callus after 3-5 weeks on selection medium. The shoots which grew into 2-3 cm were transferred for rooting on MS with $0.1 \mathrm{mg} / \mathrm{L}$ IAA, $200 \mathrm{mg} / \mathrm{L}-1$ Cefotaxime and $20 \mathrm{mg} / \mathrm{L}$ Hygromycin. The rooting plants growing into plantlets were transplanted into soil for continuous growth.

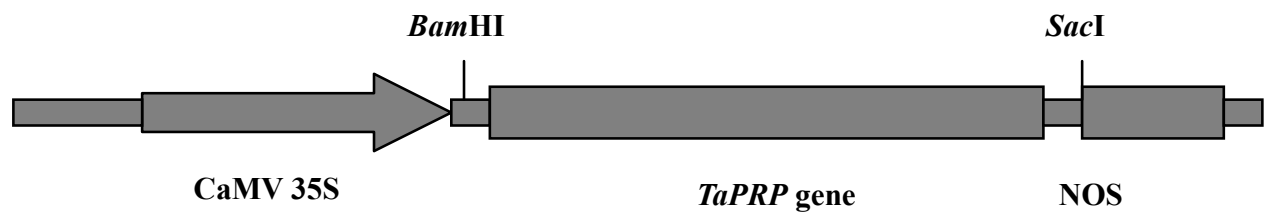

Figure 1. The structure of expression vector $\mathrm{pBI} 121$ with $T a P R P$

\subsection{PCR Analyses and Blotting Analyses for Transformed Plants}

Total plant DNA was isolated from leaves according to CTAB method (Roger et al., 1998). PCR identification of the gene was performed respectively using the DNA from the transformed plants as templates and non-transformed plant and pBI121 as control. Primers, PCR reaction mixture and conditions were the same as those in 1.3 .

Southern blotting was carried out according to the Sambrook et al. (1989) method. The DNA samples were restricted with $E c o$ R I after agarose gel electrophoresis and were transferred into nylon membrane and randomly labeled with DIG-dUTP according to the instruction of DIG DNA Labeling and Detection Kit.

Total RNA was isolated for RNA gel-blot analysis. Thirty micrograms of total RNA for each sample was separated by electrophoresis in 1\% agarose for maldehyde gels. Northern blotting analysis was performed as described by Sambrook et al. (1989). To detect the expression pattern of TaPRP, specific probes derived from the coding region were designed. The probes were labeled using the PCR DIG probe synthesis Kit (Boehringer Mannheim, Germany). Before using Northern blotting, the specific respondents to TaPRP mRNA was conformed by the hybridization with its cDNA clone, and the probes specifically recognized the corresponding cDNA (data not shown). Non transgenic tobacco plants were as the control. Primers, PCR reaction mixture and conditions were the same as those in 1.3. A photograph was taken to expose the membrane for 5-15 minutes to an X-ray film (Fuji Photo Film Co. Ltd, Tokyo, Japan).

\subsection{Cold Resistant Analysis for Transformed Plants}

Cold resistance in tobacco plants was evaluated by measuring electrolyte leakage in leaves with EC324 conductivity meter as described by Jaglo-Ottosen et al. (1998). The $\mathrm{T}_{0}$ generation transformed plants with pBI121-TaPRP and the plants transformed with pBI121 were cultivated as experimental materials. The leaves at similar position with similar size were taken out from transformed and non-transformed plants. The leaves were incubated in salt-water bath at $0,-8,-16{ }^{\circ} \mathrm{C}$ for $15 \mathrm{~min}$ with constant stirring. Then the leaves were put into the refrigerator at $4{ }^{\circ} \mathrm{C}$ for $30 \mathrm{~min}$. After electrolyte leakage was measured, the leaves were boiled for $10 \mathrm{~min}$, and electrolyte leakage was measured again. Relative conductivity rate were calculated. The conductivity determinations of every sample were repeated three times.

\section{Results}

\section{1 cDNA Cloning and Characterization of TaPRP}

The complete cDNA of wheat TaPRP was obtained using a combination of bioinformatics tools and PCR cloning. In order to obtain the full length of TaPRP gene, RT-PCR was carried out with the template of wheat total RNA and $5^{\prime}$ and $3^{\prime}$ degenerate primers of $P R P$ cDNA. A specific product of $1.1 \mathrm{~kb}$ was amplified (Figure 2). The amplified PCR product was gel-purified and inserted into the pGEMT-Easy vector. Sequence of positive clone was determined by dideoxynucleotide sequencing. Sequence analysis showed that the cDNA was $1197 \mathrm{bp}$ in length. The start codon ATG and stop codon TGA were at $6 \mathrm{bp}$ and $1142 \mathrm{bp}$, respectively. The full TaPRP cDNA sequence contained $1137 \mathrm{bp}$ with a single ORF and it encoded a peptide of 378 amino acids (Figure 3). The deduced molecular mass and isoelectric point of TaPRP were $42.19 \mathrm{Kd}$ and 9.69, respectively. The TaPRP cDNA sequence in this study was released in GenBank with accession number GQ331032. 
The similarity of amino acid sequence with the reported sequences in GenBank, including wheat (DQ286560.1), sorghum (AJ234401.1), rice (EF408055.1) and maize (AJ130830.1) were 92.6\%, 89.3\%, 73.0\%, and 73.3\%, respectively (Figure 3). The deduced secondary structure showed that 3-31aa is a membrane-spanning domain. The proline number in the whole protein accounts for $44.97 \%$ of the whole numbers amino acid, and the mass of all proline accounts for $39.95 \%$ of the mass of whole protein. These characteristics showed that TaPRP is a member of PRP family in Poaceae.

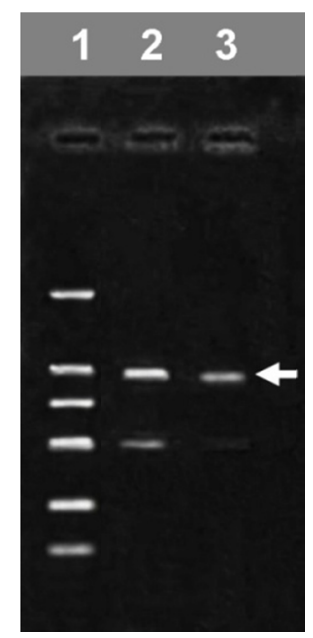

Figure 2. Agarose gel analysis of RT-PCR product of TaPRP

Note. 1: DNA molecular-weight; 2:3: PCR products, Arrow for 1.1kb RT-PCR stcrip. 
plasmids pBI121) as templates. DNA fragments of $1100 \mathrm{bp}$ were obtained from three kanamycin-survived plants, but not from the control plant and other three kanamycin-survived plants (Figure 4). The total DNA of transformants and the control were digested with EcoR I. The plants with 1100 bp nof fragment obtained were considered as transgenic plants (transformed plants) and designated transformants I, II, and III.

Southern blotting analysis, using the TaPRP as the probe, showed that all the three transformants produced differential hybridization signals, but no hybridization signal was observed in the control. This indicated that the TaPRP ORF was inserted into the genome of tobacco, but the sites of insertion were different from each other (Figure 5). The total RNA of transformants and the control were extracted respectively. Northern blotting analysis using TaPRP DNA fragment as the probe showed that all the three transformants had a differential hybridization signal, but the control did not produce any signal (Figure 6). This indicated that the TaPRP fragment was transcripted in the tobacco, but the levels of expression of TaPRP in the three transformants were not identical. The different expressions might result from the difference of inserting site or different physiological activity.

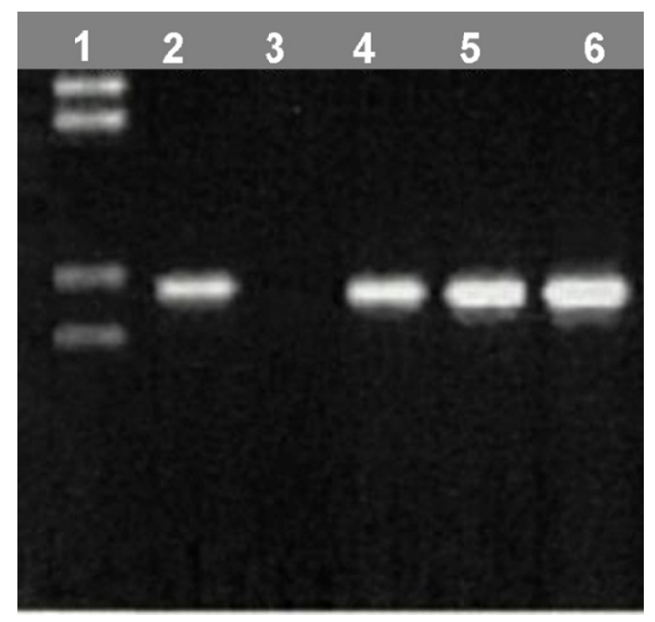

Figure 4. PCR amplification of some Kan resistant plants of transgenic tobacco

Note. 1: DNA ladder; 2: Positive control, pBI121-TaPRP Plasmid; 3: Negative control, non-transgenic plant; 4-6: 3 transgenic tobacco plants.

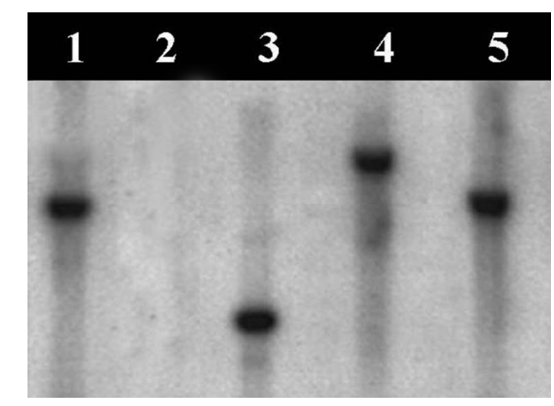

Figure 5. Southern blot analysis of transgenic plants

Note. 1: pBI121-TaPRP, positive control; 2: Untransgenic tobacco plant; 3-5: Transgenic tobacco plants. 


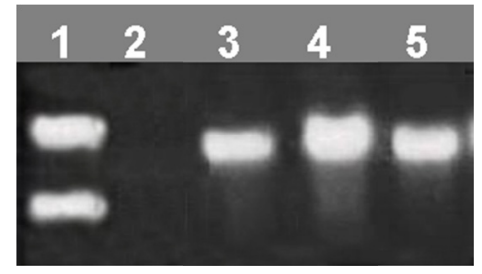

Figure 6. Expression of TaPRP in the transgenic plants detected by Northern blot

Note. 1: DNA marker; 2: Wild-type plants; 3-5: No. 1-3 transgenic tobacco seedlings TaPRP.

\subsection{Cold Resistant Experiment on the Transgenic Tobacco Plants}

Leaves from three transformants plants, and plants transformed with empty vector (no TaPRP) were frozen at the three indicated temperatures $\left(0,-8,-16{ }^{\circ} \mathrm{C}\right)$ and the extent of cellular damage was estimated by measuring electrolyte leakage (Table 1). With duration of cold stress, the electrolyte leakage from detached leaves gradually increased in different degree. This is due to the increasing cell leakage for frozen injury in leaves. At the three cold stress treatments $\left(0,-8,-16{ }^{\circ} \mathrm{C}\right)$, the relative conductivity rate in transformed plants were significantly higher than that from control plants. The results indicated that PRP protein might improve the ability of tobacco resist to cold. More stability of membrane in transformed plants could be kept under cold stress. In addition, electrolyte leakage to cold stress showed significant differences among the three cold stresses $(P<0.05)$, but no differences among the three transformed plants (Figure 7). The interactions were significant between plant and treatment $(P<0.05)$.

Table 1. Conductance rate in leaves of three transgenic tobacco plants under low temperature

\begin{tabular}{llllll}
\hline source of variation & sum of squares & freedom of motion & uniform & $F$-value & $p$-value \\
\hline Inter-plant & 9.21 & 2 & 4.60 & 0.236 & NS \\
Frozen & 4888.48 & 2 & 2444.24 & 125.135 & $* * *$ \\
Plant $\times$ Frozen & 78.13 & 4 & 19.53 & 3.115 & $*$ \\
Error & 112.87 & 18 & 6.27 & & \\
Total variance & 5088.69 & 26 & & & \\
\hline
\end{tabular}

Note. ${ }^{*}, * * *$ indicated significance $P<0.05$ and $P<0.001$ probability levels, respectively.

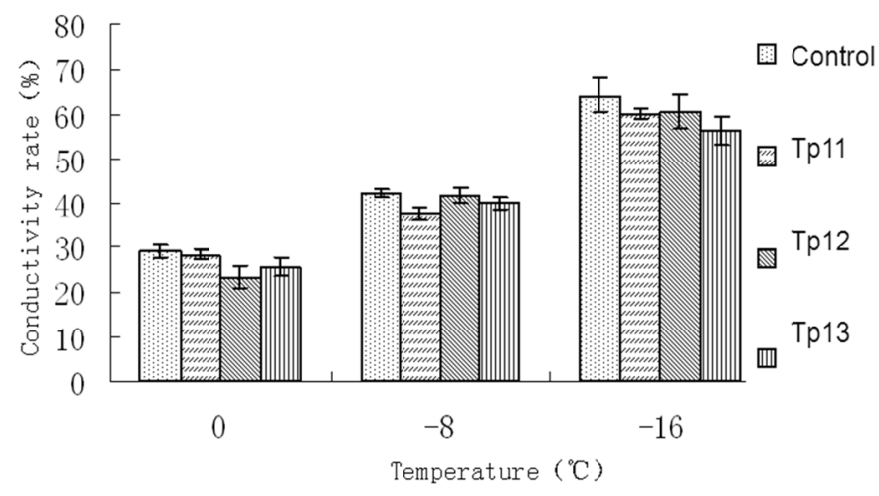

Figure 7. Conductivity rate of transgenic and non-transgenic tobacco at low temperature

Note. Conductivity rates with the same letter at the same temperature have no difference $(P<0.05)$.

\section{Discussion}

Genomic and cDNA sequences of PRPs indicate that the PRP proteins can be placed into two classes based on their primary structure. The first of these classes is characterized by $P R P$ genes isolated from carrot and soybean, 
which encode tandem copies of the pentapeptide PPVX $(K / T)$, where $\mathrm{X}$ is often $\mathrm{Y}, \mathrm{H}$, or E (Hong et al., 1990). In contrast, a second group of $P R P$ cDNAs predicts two-domain proteins containing a Pro-rich N-terminal domain and a C-terminal domain that lacks Pro-rich or repetitive sequences. This group of PRP genes includes TPRP-F1 in tomato (Salts et al., 1991). In the present study, a full length of a wheat proline-rich protein gene, named $T a P R P$ was cloned and described in its molecular characterization. TaPRP encoded a putative protein which contains 170 proline, and $44.97 \%$ of all the total number of amino acids is the protein. TaPRP represents the first subset of $P R P s$ in higher plants. Homology analysis revealed that TaPRP shared similarity with many PRPs from Poaceae. Its genebank accession number is GQ331032.

PRPs play an important role in plant development, pathogen responses and stress-resistant responses. Generally, PRPs are thought to contribute to the enhancement of cell wall structure in specific cell types during plant development, and they could fall into cross-linked or non cross-linked PRPs based on their ability to cross-link with components within the cell wall (Cassab, 1998), Both kinds of PRPs could participate into e responses to one stimulus, but might involve in different response mechanisms (Wang, 1996; Marshall et al., 1999). It has been reported that these proteins may involve interactions with other components within the extracellular matrix and possibly with proteins within the cell membrane, and thus induce cascade reactions in stress or pathogen-resistant responses (García-Gomez et al., 2000; Murphy et al., 2002). TaPRP cloned in this study has no linked tyrosine and Val-Tyr-Lys domains, belonged to non cross-linked PRP (Kieliszewski et al., 1994).

Temperature is one of the most important environmental factors in plant growth and development, crop yields and quality and species distributions in the world. Improving the cold tolerance in crops has significances for agricultural production. In recent years, cold mechanism has been deeply researched. Many cold resistant-relevant genes have been cloned from different plants and transgenic plants with cold tolerance have been obtained. These genes involve in stability of cell membrane (Los et al., 1997; Warren et al., 2000; Steponkus et al., 1998; Cyril et al., 2002; Vega et al., 2004), antioxidant and radical scavenging activity (Kang et al., 2002; Sato et al., 2001), antifreeze protein (Wallis et al., 1997; Huang et al., 2002), transcriptional activator in low temperature signal transduction (Xiang et al., 2007; Hsieh et al., 2002; Gilmour et al., 2000) and osmotic regulation (Jin et al., 2005; Su et al., 2006; Kumar et al., 2004).

The transgenic tobacco plants with TaPRP significantly deduced conductivity rate under low temperature treatment. This indicated the plants improved the freezing tolerances. But the cold tolerances mechanism of PRP might be different from those of other proteins. It has been reported that PRP involved in maintaining the stability of cell membrane under many abiotic stress. As one main components in cell cytoplast and cell wall, PRP could be an antifreeze protein in cell, or have significance in osmotic regulations. So, it is necessary to study the cold tolerance mechanism of TaPRP further.

In this study, electrolyte leakage was measured by conductivity rate under cold treatments to judge the plant cold tolerances. Conductivity rate is one index to evaluate if the cell membrane system has been injured under low temperature. Besides electrolyte leakage, contents of sugar, free praline, soluble protein, organic acids and the ingredients of membrane lipids could all be indices in evaluating plant cold tolerances. In order to unambiguously clarify the functions of TaPRP, several different detecting measures should be utilized in future experiments.

Our research proved that cold tolerance plant materials could be obtained by transgenic TaPRP, however, it should be pointed out that past researches indicated that transgenic single genes into a plant has less effective than transgenic several genes in cold tolerance. Improving the crop stress resistance by gene engineering is one important field in plant genetic transformation. Categories, transformation modes and expression characteristics of foreign genes in transformed plants should coordinate together for cold resistance. We believe that this research might be helpful for breeding new wheat cultivars with stress resistance.

\section{Acknowledgements}

This research is supported by Key Program for Natural Sciences Fund in Shandong Province in China (ZR2012CZ001) and (ZR2013CZ001). The authors appreciate Crop Science Postdoctoral Station in Shandong Agricultural University. Parts of the experiment were aided by Jibaite Biotec Co. (Beijing, China).

\section{References}

Cassab, G. I. (1998). Plant cell wall proteins. Annu. Rev. Plant Phsyiol. Mol. Biol., 49, 281-309. http://dx.doi.org/10.1146/annurev.arplant.49.1.281 
Chen, C. Q., Mau, S. L., \& Clarke, A. E. (1993). Nucleotide sequence and style-specific expression of a novel proline-rich protein gene from Nicotiana alata. Plant Mol. Biol., 21, 391-395. http://dx.doi.org/10.1007/BF00019955

Cyril, J., Powel, G. L., \& Duncan, R. R. (2002). Changes in membrane polar lipid fatty acids of seashore paspalum in response to low temperature exposure. Crop Sci., 42, 2031-2037. http://dx.doi.org/10.2135/cropsci2002.2031

Datta, N., LaFayette, P. R., Kroner, P. A., Nagao, R. T., \& Key, J. L. (1993). Isolation and characterization of three families of auxin down regulated cDNA clones. Plant Mol. Biol., 21, 859-869. http://dx.doi.org/10.1007/BF00027117

Deutch, C. E., \& Winicov, I. (1995). Post-transcriptional regulation of a salt-inducible alfalfa gene encoding a putative chimerical proline-rich cell wall protein. Plant Mol. Biol., 27, 411-418. http://dx.doi.org/10.1007/BF00020194

García-Gomez, B. I., Campos, F., Hernández, M., \& Covarrubias, A. A. (2000). Two bean cell wall proteins more abundant during water deletion are high in proline and interact with a plasma membrane protein. Plant J., 22, 277-288. http://dx.doi.org/10.1007/s00425-006-0423-9

Gilmour, S., \& Sebolt, A. M. (2000). Over-expression of the Arabidopsis $C B F 3$ transcriptional activator mimics multiple biochemical changes associated with cold acclimation. Plant Physiol., 124, 1854-1865. http://dx.doi.org/10.1104/pp.124.4.1854

He, C. Y., Zhang, J. S., \& Chen, S. Y. (2002). A soybean gene encoding a proline-rich protein is regulated by salicylic acid, an endogenous circadian rhythm and by various stresses. Theor. Appl. Genet., 104, 1125-1131. http://dx.doi.org/10.1007/s00122-001-0853-5

Hong, J. C., Nagao, R. T., \& Key, J. L. (1990). Characterization of a proline rich cell wall protein gene family of soybean. J. Biol. Chem., 265, 2470-2475.

Hsieh, T. H., Lee, J. T., Yang, P. T., Chiu, L. H., Charng, Y. Y., Wang, Y. C., \& Chan, M. T. (2002). Heterology expression of the Arabidopsis C-repeat/dehydration response element binding Factor 1 gene confers elevated tolerance to chilling and oxidative stresses in transgenic tomato. Plant Physiol., 129, 1086-1094. http://dx.doi.org/10.1104/pp.003442

Huang, T., \& Duman, J. G. (2002). Cloning and characterization of a thermal hysteresis (antifreeze) protein with DNA-binding activity from winter bittersweet nightshade Solanum dulcamara. Plant Mol. Biol., 48(4), 339-350. http://dx.doi.org/10.1023/A:1014062714786

Jaglo-Ottosen, K. R., Gilmour, J., \& Zarka, D. G. (1998). Arabidopsis CBF1 over expression induces COR genes and enhances freezing tolerance. Science, 280, 104-106. http://dx.doi.org/10.1126/science.280.5360.104

Jin, J. F., Gao, Q., Chen, Y., \& Wang, J. H. (2005). Transfer of Arabidopsis CBF1 Gene Leads to Increased Proline Contents in Rice Plants. Chinese $J$ Cell Bio., 27, 73-76. http://dx.doi.org/10.1126/science.280.5360.104

Kang, H. M., \& Saltveit, M. E. (2002). Reduced chilling tolerance in elongating cucumber seedlings radicles is relater to their reduced antioxidant enzyme and DPPH-radical scavenging activity. Plant Physiol., 115, 244-250. http://dx.doi.org/ 10.1007/s11816-009-0102-y

Kieliszewski, M. J., \& Lamport, D. T. A. (1994). Extensin: Repetitive motifs, functional sites, post-translational codes, and phylogeny. Plant J., 5, 157-172. http://dx.doi.org/10.1007/10.1007/s00425-008-0734-0

Kumar, S., Dhingra, A., \& Daniel, H. (2004). Plastid-expressed betaine aldehyde dehydrogenase gene in carrot cultured cells, roots and leaves confer enhanced salt tolerance. Plant Physiol., 136, 2843-2854. http://dx.doi.org/10.1104/pp.104.045187

Los, D. A., Ray, M. K., \& Murata, N. (1997). Differences in the control of the temperature-dependent expression of four genes for desaturases in Synechocystis sp. PCC 6803. Mol. Microbiol., 25, 1167-1175. http://dx.doi.org/10.1046/j.1365-2958.1997.5641912.x

Marshall, J. G., Dumbro, V. E. B., Thatcher, B. J., Martin, B., Rutledge, R. G., \& Blumwald, E. (1999). Synthesis and oxidative insolubilization of cell-wall proteins during osmotic stress. Planta, 208, 401-408. http://dx.doi.org/10.1007/s004250050575 
Murphy, A. S., Hoogner, K. R., Peer, W. A., \& Taiz, L. (2002). Identification, purification, and molecular cloning of N-1-naphthylphtalmic acid-binding plasma membrane-associated aminopeptidases from Arabidopsis. Plant Physiol., 128, 935-950. http://dx.doi.org/10.1104/pp.010519.

Ogawa, M., Kusano, T., Koizumi, N., Katsumi, M., \& Sano, H. (1999). Gibberellin-responsive genes: high level of transcript accumulation in leaf sheath meristematic tissue from Zea mays L. Plant Mol. Biol., 40, 645-657. http://dx.doi.org/10.1023/A:1006291917591

Roger, S. D., \& Bendich, A. J. (1988). Extraction of DNA from plant tissues. In S. B. Gelvin, R. A. Schilperoot, \& D. P. S. Verma (Eds.), Plant Molecular Biology Manual (A6: 1-10). Dordrecht: Kluwer. http://dx.doi.org/10.1007/978-94-017-5294-7_6

Salts, Y., Wachs, R., Gruissem, W., \& Barg, R. (1991). Sequence coding for a novel proline-rich protein preferentially expressed in young tomato fruit. Plant Mol. Biol., 17, 149-150. http://dx.doi.org/10.1007/BF00036818

Sambrook, J., Fritsch, E. F., \& Maniatis, T. (1989). Molecular Cloning: A Laboratory Manual (2nd ed.). New York: Cold Spring Harbor Laboratory Press.

Sato, Y., Murkami, T., Funatsuki, H., Matsuki, S., Saruyama, H., \& Tanida, M. (2001). Heat shock-mediated $A P X$ gene expression and protection against chilling injury in rice seedlings. J. Expe. Bot., 52, 145-151. $\mathrm{http} / / / \mathrm{dx}$.doi.org/10.1093/jexbot/52.354.145

Showalter, A. M. (1993). Structure and function of plant cell wall proteins. Plant Cell, 5, 9-23. http://dx.doi.org/10.1105/tpc.5.1.9

Steponkus, P. L., Uemura, M., Joseph, R. A., Gilmour, S. J., \& Thomashow, M. F. (1998). Mode of action of the CoR15a gene on the freezing tolerance of Arabidopsis thaliara. Pro. Nat. Acad. Sci., 95(24), 14570-14575. http://dx.doi.org/10.1073/pnas.95.24.14570

Su, J., Hirji, R., Zhang, L., He, C. K., Selvaraj, G., \& Wu, R. (2006). Evaluation of the stress-inducible production of choline oxidase in transgenic rice as a strategy for producing the stress-protectant glycine betaine. J. Exp. Bot., 57(5), 1129-1135. http://dx.doi.org/10.1007/s11816-012-0266-8

Subramaniam, K., Ranie, J., Srinivasa, B. R., Sinha, A. M., \& Mahadevan, S. (1994). Cloning and sequence of cDNA encoding a novel hybrid proline-rich protein associated with cytokinin-induced haustoria formation in Cuscuta reflexa. Gene, 141, 207-210. http://dx.doi.org/10.1016/0378-1119(94)90572-X

Vega, S. E., Delrio, A. H., Bamber, J. B., \& Palta, J. P. (2004). Evidence for the up-regulation of stearogl-ACP $(\Delta 9)$ desaturase gene expression during cold acclimation. Amer. J. Potato Res., 81, 125-135. http://dx.doi.org/10.1007/BF02853610

Wallis, F. G., Wang, H., \& Guerra, D. J. (1997). Expression of a synthetic antifreeze protein in potato reduces electrolyterelease at freezing temperatures. Plant Mol. Bio., 35(3), 323-330. http://dx.doi.org/10.1023/A:1005886210159

Wang, G. L., \& Fang, H. J. (1998). Principles and Techniques in Plant Gene Engineering. Beijing: Science Press.

Wang, R. (1996). Expression and Function Analyses of a Gene Family Encoding a Novel Class of Proline-rich Proteins in Rice. Institute of Chinese Academy of Sciences, the degree of Doctor Philosophy.

Warren, G. J., Thorlby, G. J., \& Knight, M. R. (2000). The molecular biological approach to understanding freezing tolerance in the model plant Arabidopsis thaliana. Env. Stressors Gene Re., 1, 245-258. http://dx.doi.org/10.1016/S1568-1254(00)80019-4

Wilson, R. C., Long, F., \& Maruoka, E. M. (1993). A new proline-rich early nodulin from Mediccrgo trunccrtulcr is highly expressed in nodule meristematic cells. Plant Cell, 6, 1265-1275. http://dx.doi.org/10.1105/tpc.6.9.1265

Wyatt, R. E., Nagao, R. T., \& Key, J. L. (1992). Patterns of soybean proline-rich protein gene expression. Plant Cell, 4, 99-110. http://dx.doi.org/10.1105/tpc.4.1.99

Xiang, D. J., Zhang, Y., \& Yin, K. D. (2007). Transformation of ICE1 Gene Mediated by Agrobacterium Improves Cold Tolerance in Transgenic Rice. Chinese Journal of Rice Science, 21(5), 482-486. 
Yasuda, E., Ebinuma, H., \& Wabiko, H. (1997). A novel glycine-rich/hydrophobic 16 kDa polypeptide gene from tobacco: similarity to proline-rich protein genes and its wound-inducible and developmental-regulated expression. Plant Mol. Biol., 33, 667-678. http://dx.doi.org/10.1023/A:1005714119561

Yu, L. X., Chamberl, H., Lafontaine, J. G., \& Tabaeizadeh, Z. (1996). Negative regulation of gene expression of a novel proline-, threonine- and glycine-rich protein by water stress in Lycopersicon chilense. Genome, 39, 1185-1193. http://dx.doi.org/10.1139/g96149

\section{Copyrights}

Copyright for this article is retained by the author(s), with first publication rights granted to the journal.

This is an open-access article distributed under the terms and conditions of the Creative Commons Attribution license (http://creativecommons.org/licenses/by/3.0/). 